\title{
Os cuidados de enfermagem aos trabalhadores rurais que fazem uso de agrotóxico na colheita de acerola no povoado Jenipapo, Lagarto/SE
}

Este estudo teve como objetivo avaliar os riscos ocupacionais presentes no processo de trabalho em coletores de acerola do povoado Jenipapo de Lagarto/SE. Trata-se de um estudo transversal, descritivo, exploratório, de campo com abordagem quantitativa, realizado com 26 trabalhadores que atenderam os seguintes critérios de inclusão da pesquisa: estar realizando suas atividades de enfermagem no período em que o pesquisador estiver coletando os dados e ser catador da safra de acerola, em atividade. 0 estudo foi realizado no período de fevereiro a março de 2015 . Foi constatado que $88 \%$ destes trabalhadores eram mulheres enquanto apenas $12 \%$ eram homens, com faixa etária entre 33 a 68 anos de idade, (27\%) são casados, amasiados e solteiros, $11 \%$ separados e $4 \%$ divorciados. $63 \%$ disseram que trabalham de 8 a 10 horas no campo enquanto 38\% afirmaram trabalhar de 6 a 8 horas na agricultura. Sobre o estado de saúde, $42 \%$ disseram estar regular, $23 \%$ ótimo e $19 \%$ responderam que está bom. Conclui-se que que a Política de Saúde do Trabalhador não é tão eficaz, tendo em vista a falta de fiscalização, de acompanhamento técnico e o não cumprimento da legislação que controla a comercialização dos agrotóxicos, propiciando neste sentido, acesso indiscriminado aos mesmos e com isso implicando na possibilidade de contaminação à saúde e ao meio ambiente e a saúde destes trabalhadores.

Palavras-chave: Saúde do Trabalhador; Políticas de saúde; Agrotóxico.

\section{Nursing care for rural workers using pesticide in the acerola harvest in Jenipapo, Lagarto/SE}

This study aimed to evaluate the occupational risks present in the work process in acerola collectors in Jenipapo de Lagarto/SE. This is a cross-sectional, descriptive, exploratory, field study with a quantitative approach, carried out with 26 workers who met the following criteria for inclusion in the research: to be carrying out their nursing activities in the period in which the researcher is collecting data and to be picker of the acerola crop, in activity. The study was carried out from February to March 2015 . It was found that $88 \%$ of these workers were women while only $12 \%$ were men, aged between 33 and 68 years old, ( $27 \%$ ) are married cohabited and single, $11 \%$ separated and $4 \%$ divorced. $63 \%$ said they work 8 to 10 hours in the field while $38 \%$ said they work 6 to 8 hours in agriculture. Regarding the state of health, $42 \%$ said they were regular, $23 \%$ excellent and $19 \%$ said it was good. It is concluded that the Worker's Health Policy is not as effective, in view of the lack of inspection, technical follow-up and non-compliance with the legislation that controls the marketing of pesticides, providing in this sense, indiscriminate access to them and with this implying the possibility of contamination to health and the environment and the health of these workers.

Keywords: Occupational Health; Health policies; Pesticides.

Topic: Epidemiologia

Reviewed anonymously in the process of blind peer
Received: 06/06/2020

Approved: 19/08/2020
Elvis das Neves de Souza (DD

Centro Universitário UniAges, Brasil

http://lattes.cnpq.br/2100716023682132

http://orcid.org/0000-0001-8652-4603

elvis.nsouza@hotmail.com

Carmen Luiza Rodrigues de Jesus Santos (iD)

Centro Universitário UniAges, Brasil

http://lattes.cnpq.br/3597049492460192

http://orcid.org/0000-0002-0398-6149

carmemluiza2810@gmail.com

Ana Paula Gomes Soares Pereira (iD)

Universidade Estadual de Minas Gerais, Brasil

http://lattes.cnpq.br/3631825469916595

http://orcid.org/0000-0002-1050-6035

anapaulagsoares@yahoo.com.br

\begin{tabular}{l} 
Renan Sallazar Ferreira Pereira (DD \\
Universidade Federal do Tocantins, Brasil \\
http://lattes.cnpq.br/8154326371029706 \\
\hline $\begin{array}{l}\text { http://orcid.org/0000-0001-5140-4046 } \\
\text { renansallazar@mail.uft.edu.br }\end{array}$ \\
Humberto Aparecido Faria (D) \\
Centro Universitário UniAges, Brasil \\
http://lattes.cnpq.br/3226370935768571 \\
http://orcid.org/0000-0002-9784-5506 \\
humbertofaria@yahoo.com.br \\
Tatiane Jesus dos Santos (D) \\
Centro Universitário UniAges, Brasil \\
http://lattes.cnpq.br/0910749444505327 \\
$\underline{\text { http://orcid.org/0000-0002-0603-5402 }}$ \\
tatianejsantos1993@hotmail.com
\end{tabular}

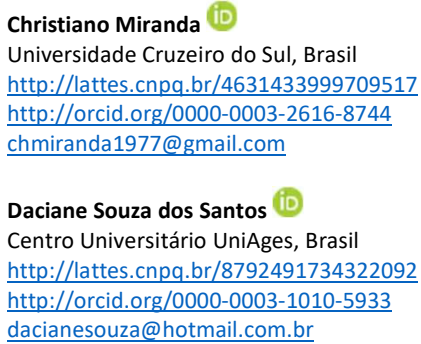

Referencing this:

SOUZA, E N.; SANTOS, C. L. R. J.; PEREIRA, A. P. G. S.; PEREIRA, R. S. F.; FARIA, H. A.; SANTOS, T. J.; MIRANDA, C.; SANTOS, D. S.. Os cuidados de enfermagem aos trabalhadores rurais que fazem uso de agrotóxico na colheita de acerola no povoado Jenipapo, Lagarto/SE. Scire Salutis, v.10, n.3, p.97-103, 2020. DOI: http://doi.org/10.6008/CBPC22369600.2020 .003 .0012

(9600.2020.003.0012 


\section{INTRODUÇÃO}

Os agrotóxicos tiveram crescimento de mercado mundial de $93 \%$ nos últimos dez anos. Não no Brasil, que teve avanço maior que 190\%. Um mercado nacional que em 2002 representava $\mathrm{R} \$ 2,5$ bilhões chega, passados dez anos, à cifra de $R \$ \$ 8,9$ bilhões. Os estudos do impacto desses produtos não acompanham a própria liberação do comércio e, menos ainda, a informação sobre o uso. O resultado: mais pessoas estão morrendo por agrotóxico agrícola (MELO et al., 2016).

No Brasil, foram 4.789 casos registrados de intoxicação por esses produtos em 2010. No período, foram 86.700 casos totais de intoxicação sob diversos agentes, como agrotóxicos, animais peçonhentos, raticidas e domissanitários. Os óbitos causados por veneno representam, por exemplo, 10\% das mortes por trânsito nas estradas brasileiras; e o Brasil é o quarto país onde mais se morre no trânsito (ARAÚJO, 2010, VIERO et al., 2016).

A média é acompanhada no levantamento de mortes entre 2001 e 2010. O Nordeste apresenta 37,7\% das mortes, seguido de Sudeste $(24,52 \%)$, Sul $(18,40 \%)$, Centro-Oeste $(17,24 \%)$ e Norte $(2,65 \%)$. São 17 categorias de circunstâncias apontadas no levantamento: acidente individual, acidente coletivo, acidente ambiental, ocupacional, uso terapêutico, prescrição médica inadequada, erro de administração, automedicação, abstinência, abuso, ingestão de alimentos, tentativa de suicídio, tentativa de aborto, violência/homicídio, uso indevido, ignorada e outra (ABREU et al., 2014).

As repercussões à saúde dos trabalhadores rurais e à comunidade circunvizinha exposta aos agrotóxicos representam um problema de saúde pública alvo de ações governamentais, no intuito de atuar de forma integrada na promoção da saúde, na prevenção dos agravos e na participação e controle social. Dessa forma, o objetivo desse trabalho é avaliar os riscos ocupacionais presentes no processo de trabalho em coletores de acerola do povoado Jenipapo de Lagarto/SE.

\section{METODOLOGIA}

Trata-se de um estudo transversal, descritivo, exploratório, de campo com abordagem quantitativa, realizado com 26 trabalhadores que atenderam os seguintes critérios de inclusão da pesquisa: estar realizando suas atividades de enfermagem no período em que o pesquisador estiver coletando os dados e ser catador da safra de acerola, em atividade. O estudo foi realizado no período de fevereiro a março de 2015 após aprovação do Comitê de Ética em Pesquisa da Faculdade AGES, sob Parecer no. 320215. É valido ainda ressaltar que os procedimentos éticos foram corroborados com os preceitos deliberados pela Resolução $466 / 12$.

A coleta foi realizada durante a jornada de trabalho, no dia e horário agendado, feita após assinatura do termo do Termo Livre e Esclarecido em duas vias e previamente explicado. Para a coleta de dados foi utilizado um único formulário constituído das seguintes variáveis: Sociodemográfico, abrangido por dados pessoais e profissionais, atrelado as variáveis de morbidade referida e uso de agrotóxico. Os resultados foram inseridos na planilha do programa de computador Microsoft Office Excel 2010, apresentados na forma de 
tabelas e figuras, com frequências absoluta e relativa.

\section{RESULTADOS}

Pelos dados da Tabela 1, verifica-se que a população investigada está entre $88 \%$ mulheres e apenas 12\% homens, com faixa etária entre 33 a 68 anos de idade. Averiguou-se a respeito do estado civil dos participantes que a grande maioria (27\%) são casados, amasiados e solteiros. Enquanto que $11 \%$ afirmaram ser separados, e os $4 \%$ restantes informaram ser viúvos e divorciados.

Tabela 1: Distribuição dos trabalhadores rurais segundo as variáveis sociodemográficas. Povoado Jenipapo, Lagarto/SE, 2015.

\begin{tabular}{|c|c|c|}
\hline Variáveis & $\mathbf{n}$ & (\%) \\
\hline \multicolumn{3}{|l|}{ Sexo } \\
\hline Feminino & 23 & 88,0 \\
\hline Masculino & 3 & 12,0 \\
\hline Total & 26 & 100,0 \\
\hline \multicolumn{3}{|l|}{ Faixa etária } \\
\hline $20-30$ & - & \\
\hline $30-40$ & 12 & 46,0 \\
\hline $40-50$ & - & 54,0 \\
\hline $50-60$ & - & \\
\hline Mais de 60 & 14 & \\
\hline Total & 26 & 100,0 \\
\hline \multicolumn{3}{|l|}{ Estado civil } \\
\hline Solteiro & 7 & 27,0 \\
\hline Casado & 7 & 27,0 \\
\hline Viúvo & 1 & 4,0 \\
\hline Separado & 3 & 11,0 \\
\hline Divorciado & 1 & 4,0 \\
\hline Amasiado & 7 & 27,0 \\
\hline Total & 26 & 100,0 \\
\hline \multicolumn{3}{|l|}{ Escolaridade } \\
\hline Ensino Fundamental & 2 & 7 \\
\hline Ensino Médio & 1 & 4 \\
\hline Ensino Fundamental incompleto & 21 & 81 \\
\hline Ensino Médio incompleto & - & 0 \\
\hline Não escolarizado & 2 & 8 \\
\hline Total & 26 & 100 \\
\hline \multicolumn{3}{|l|}{ Etnia } \\
\hline Branco & 4 & 15 \\
\hline Negro & 4 & 15 \\
\hline Mulato & 7 & 27 \\
\hline Amarelo & 2 & 8 \\
\hline Mestiço & 9 & 35 \\
\hline Total & 26 & 100 \\
\hline
\end{tabular}

Quanto ao nível de escolaridade $81 \%$ afirmaram ter o ensino fundamental incompleto, enquanto que os demais ( $8 \%, 7 \%$ e $4 \%)$ afirmaram respectivamente não ser alfabetizado, ter ensino fundamental completo e ensino médio completo, conforme pode observar pela Tabela 1.0 estudo também investigou a etnia desses trabalhadores rurais e foi constatado conforme observa a Tabela 1 que a maioria (37\%) são mestiços e outros $27 \%$ são mulatos e apenas $15 \%$ são da cor branca.

Ao analisar esses dados, é importante ressaltar que as pessoas que se expõem ao sol de forma prolongada e frequente, por atividades profissionais ou de lazer, como os trabalhadores rurais com exposição cumulativa e excessiva durante os 10 a 20 anos de vida, aumenta muito o risco de câncer de pele. Tem-se ciência ainda de que a cor de pele mais clara é a mais propensa a doenças relacionadas à doença de pele. 
Tabela 2: Distribuição dos trabalhadores rurais conforme processo de trabalho. Povoado Jenipapo, Lagarto/SE, 2015.

\begin{tabular}{lll}
\hline Variáveis & $\mathbf{n}$ & (\%) \\
\hline Tipo de trabalho & & 31 \\
Leve & 8 & 46 \\
Pouco pesado & 12 & 23 \\
Pesado & 6 & 100 \\
Total & 100 & 0 \\
Horas de trabalho no campo & & 38 \\
Menos de 6 horas & - & 62 \\
6 a 8 horas & 10 & 0 \\
8 a 10 horas & 16 & 100 \\
Mais de 10 horas & - & 15 \\
Total & 26 & 19 \\
Produtos químicos usados & & 4 \\
Agrotóxico & 4 & 62 \\
Fertilizantes químicos & 4 & 0 \\
Nenhum & 5 & 100 \\
Não souberam responder & 1 & 16 \\
Total & - & 26 \\
\hline
\end{tabular}

Sobre o tempo de serviço no campo, as respostas variaram entre 2 anos a 40 anos de serviços. A renda familiar de acordo com as respostas dos entrevistados variou entre 200 reais a 600 reais (abaixo do salário mínimo fixado em lei). Os entrevistados afirmaram ainda que os dependentes dessa renda estão entre 2 a 6 pessoas numa mesma residência. O que chama a atenção sobre a qualidade de vida desses trabalhadores. Pois, além de ter uma remuneração muito baixa, a condição de trabalho tem um aspecto físico pouco pesado.

Tabela 3: Condições de saúde dos trabalhadores rurais. Povoado Jenipapo, Lagarto/SE, 2015.

\begin{tabular}{|c|c|c|}
\hline Variáveis & $\mathbf{n}$ & (\%) \\
\hline \multicolumn{3}{|c|}{ Classificação do estado de saúde } \\
\hline Ótimo & 6 & 23 \\
\hline Bom & 5 & 19 \\
\hline Regular & 11 & 42 \\
\hline Ruim & 1 & 4 \\
\hline Péssimo & 3 & 12 \\
\hline Total & 26 & 100 \\
\hline \multicolumn{3}{|c|}{ Queixa-se de problemas de saúde } \\
\hline Sim & 15 & 58 \\
\hline Não & 11 & 42 \\
\hline Total & 26 & 100 \\
\hline \multicolumn{3}{|c|}{ Realização de tratamento dos problemas } \\
\hline Não & 7 & 27 \\
\hline Sim & 8 & 31 \\
\hline Não responderam & 11 & 42 \\
\hline Total & 26 & 100 \\
\hline \multicolumn{3}{|c|}{ Local onde realizam o tratamento } \\
\hline Centro de Saúde & 4 & 16 \\
\hline Hospital & - & 0 \\
\hline Consultório particular & 4 & 15 \\
\hline Farmácia & - & 0 \\
\hline Não se manifestaram & 18 & 69 \\
\hline Total & 26 & 100 \\
\hline
\end{tabular}

Notou-se que $31 \%$ consideram o trabalho leve e apenas $23 \%$ acha o trabalho pesado. Contrariando as respostas, acredita-se que este tipo de trabalho é pesado de maneira que ganham mal e consequentemente não se alimentam de forma adequada, além disso, o tempo de trabalho que segundo a pesquisa $63 \%$ disseram que trabalham de 8 a 10 horas no campo enquanto $38 \%$ afirmaram trabalhar de 6 a 
8 horas na agricultura. Conforme é possível analisar através da Tabela 2. Quanto a classificação sobre o seu estado de saúde, percebeu-se que $42 \%$ disseram estar regular, 23\% afirmaram estar ótimo, 19\% responderam que está bom, $12 \%$ disseram estar péssimo e $4 \%$ concordaram que seu estado de saúde está ruim, sendo vistos os dados na tabela 3 .

De acordo com a Tabela 3, 42\% dos entrevistados não responderam se estão fazendo algum tipo de tratamento com relação as dores, só $31 \%$ responderam que estão fazendo e outros $27 \%$ afirmaram que não estão fazendo tratamento. Ao serem questionados sobre onde estão realizando o tratamento, $69 \%$ responderam não se manifestaram, 16\% disseram que é no Centro de Saúde do próprio povoado em que reside e $15 \%$ afirmaram que é em consultório particular.

\section{DISCUSSÃO}

Ao analisar também o perfil sócio demográfico dos participantes, conclui-se que em virtude de seu nível de escolaridade ser baixa, os mesmos encontram-se em estado de vulnerabilidade no que tange a manipulação destas substâncias, o que dificulta o entendimento das informações técnicas e a não utilização de equipamentos de proteção individual durante a aplicação pela maioria dos trabalhadores.

A renda familiar de acordo com as respostas dos entrevistados variou entre 200 reais a 600 reais (abaixo do salário mínimo fixado em lei). Acredita-se que isso seja reflexo da agricultura e de uma desigualdade de renda que a sociedade brasileira apresenta-se por falta de incentivo e valorização de política pública aos agricultores rurais quanto à importância da agricultura para o abastecimento de alimentos para a população mundial, como também a desvalorização das muitas atividades feitas pelos agricultores no seu sistema produtivo que são altamente penosas e rotineiras, principalmente aquelas que são desenvolvidas sem tecnologia avançada e sim mais manual e de uso frequente de agrotóxicos (ANDRADE, 2005).

Os entrevistados afirmaram ainda que os dependentes dessa renda estão entre 2 a 6 pessoas numa mesma residência. $\mathrm{O}$ que chama a atenção sobre a qualidade de vida desses trabalhadores. Pois, além de ter uma remuneração muito baixa, a condição de trabalho tem um aspecto físico pouco pesado. Segundo um autor: 'tradicionalmente, o tema das condições de vida, trabalho, saúde e doença dos trabalhadores rurais no Brasil evoca estereótipos entre eles a associação com atividades rudimentares, trabalhadores empobrecidos, socialmente marginalizados e intoxicados pelos agrotóxicos'.

Desse modo, as queixas mais frequentes com relação ao seu estado de saúde em virtude do trabalho no campo foram: dor na coluna, dor de cabeça, tontura, dor nas pernas. De fato, segundo a pesquisa de campo das principais infeç̧ões frequentes em função do uso de agrotóxicos ou fertilizantes químicos mais frequentes foram: náuseas, dermatite, fadiga, inflamações mucosas, ansiedade, irritabilidade, edema, insônia, mal-estar generalizado, tontura, alergias, dor no estômago, astenia, alteração da urina, câimbra e vômito. As doenças mais frequentes das opções dadas foram: dor nas costas, infarto, derrame, varizes, cólica renal, cálculo renal, doenças venéreas, infecção urinária, doença respiratória (BAULI et al., 2014).

Analisando as condições econômicas e o tempo de trabalho no campo, acreditam que esses agricultores estão bastante vulneráveis, pois os pequenos sinais que o corpo emite podem ser um alerta de 
outro problema muito mais grave. Das principais intoxicações crônicas que mais ocorreu em função do uso de agrotóxicos ou dos fertilizantes químicos foi à depressão (BOMBARD, 2011). Os efeitos deletérios à saúde humana são descritos por alterações nos sistemas nervoso, cardiovascular, respiratório, na pele, nos olhos, além de alterações hematológicas e reações alérgicas aos agrotóxicos. Além disso, a sintomatologia apresentada nos casos de intoxicação por agrotóxicos pode ser confundida com outros agravos, pois os trabalhadores não associam sintomas como astenia, náuseas, vômitos, cefaleia, dificuldade respiratória e dores abdominais à exposição a este agente de risco (CARNEIRO, 2014; GÓMEZ, 2013).

Segundo os agricultores, atribuíram à intoxicação sofrida a: o clima, o tempo de exposição, manejo com venenos, falta de EPI e o seu uso inadequado (VIERO, et al., 2016) E dentre os equipamentos de proteção individual e coletivo que faz uso foram citados: a luva, máscara, bota fechada, chapéu de palha, camisa de manga longa, óculos e calça. E as maiores dificuldades para os agricultores em trabalhar com o cultivo da acerola são: pegar baldes pesadas, remuneração baixa, mal cheiro do esterco, o mal cheiro da pulverização, comprador, exposição ao sol, os venenos (MARTINS et al., 2013).

\section{CONCLUSÕES}

Nesse contexto, pode-se dizer que a Política de Saúde do Trabalhador não é tão eficaz. Logo, que se percebe a indigência de implantação de uma estratégia de busca ativa desses casos para que se possa ampliar o conhecimento sobre os efeitos crônicos à saúde das populações expostas a esses produtos, gerando subsídios para ações de prevenção de novos casos e de redução de sua gravidade. Mediante o conhecimento dos principais agentes químicos usados e das circunstâncias da intoxicação.

Torna-se relevante citar aqui neste espaço, em relação a fragilidade das políticas de fiscalização e de acompanhamento técnico e o não cumprimento da legislação que controla a comercialização dos agrotóxicos, propiciando neste sentido, acesso indiscriminado aos mesmos e com isso implicando na possiblidade de contaminação à saúde e ao meio ambiente.

\section{REFERÊNCIAS}

ABREU, P. H. B.; ALONZO, H. G. A.. Trabalho rural e riscos à saúde: uma revisão sobre o "uso seguro" de agrotóxicos no Brasil. Ciência \& Saúde Coletiva, v.19, n.10, p.4197-4208, 2014.

ANDRADE, M. C.. A terra e o homem no Nordeste: contribuição ao estudo da questão agrária no Nordeste. 7 ed. São Paulo: Cortez, 2005.

\section{ARAÚJO, F. V.. Intoxicação por agrotóxicos em} trabalhadores rurais: uma revisão bibliográfica. Monografia (Especialização em Enfermagem do Trabalho) - Universidade Estadual do Ceará, Fortaleza, 2010.

BAULI, J. D.; BURIOLA, A. A.; OLIVEIRA, M. L. F.; ARNAUTS, I.; SECCO, I. L.. Intoxicação por agrotóxico clandestino vivenciada por famílias de agricultores rurais: um desafio para o cuidado a saúde. 2014.
BOMBARDI, L. M.. Intoxicação e morte por agrotóxicos no Brasil: a nova versão do capitalismo oligopolizado. Bol. Dataluta, p.1-21, 2011.

CARNEIRO, F. F.. Os impactos dos agrotóxicos na saúde, trabalho e ambiente no contexto do agronegócio no Brasil. In: CONFERÊNCIA NACIONAL DE SAÚDE DOS TRABALHADORES E TRABALHADORAS, 4. Anais. 2014.

GÓMEZ, C. M.. Avanços e entraves na implementação da Política Nacional de Saúde do Trabalhador. Revista Brasileira de Saúde. Ocupacional, São Paulo, v38, n.127, 2013. DOI: http://dx.doi.org/10.1590/S0303-76572013000100004

MARTINS, C. L.; JACONDINO, M. B.; ANTONIOLLI, L. BRAZ, D. L.; BAZZAN, J. S.; GUANILO, M. E. E.. Equipamentos de proteção individual: a perspectiva de trabalhadores que sofreram queimaduras no trabalho. Rev. Enferm. UFSM, v.3, 2013. 
MELO, W. F. A.; MARACAJÁ, P. B.; MELO, W. F.; OLIVEIRA, T.

L. L.; PIMENTA, T. A.; ANDRADE, A. B. A.. Utilização de agrotóxicos e os riscos à saúde do trabalhador rural. Rev.

Bra. Edu. Saúde, v.6, n.2, p.26-30, 2016
VIERO, C. M.; CAMPONOGARA, S.; CEZAR-VA, M. R.; COSTA, V. Z.; BECK, C. L. C.. Sociedade de risco: o uso dos agrotóxicos e implicações na saúde do trabalhador rural. Esc. Anna Nery, v.20, n.1, 2016. DOI:

https://doi.org/10.5935/1414-8145.20160014

A CBPC - Companhia Brasileira de Produção Científica (CNPJ: 11.221.422/0001-03) detém os direitos materiais desta publicação. Os direitos referem-se à publicação do trabalho em qualquer parte do mundo, incluindo os direitos às renovações, expansões e disseminações da contribuição, bem como outros direitos subsidiários. Todos os trabalhos publicados eletronicamente poderão posteriormente ser publicados em coletâneas impressas sob coordenação da Sustenere Publishing, da Companhia Brasileira de Produção Científica e seus parceiros autorizados. Os (as) autores (as) preservam os direitos autorais, mas não têm permissão para a publicação da contribuição em outro meio, impresso ou digital, em português ou em tradução. 